\title{
Adapting pre-hospital stroke triage systems to expanding thrombectomy indications
}

\author{
Mayank Goyal ${ }^{1,2}$ (D) Johanna M. Ospel ${ }^{3,4}$ \\ Received: 8 December 2020 / Accepted: 5 January 2021 / Published online: 13 January 2021 \\ (C) The Author(s), under exclusive licence to Springer-Verlag GmbH, DE part of Springer Nature 2021
}

Acute ischemic stroke (AIS) leads to severe disability if left untreated, particularly when it is caused by a large vessel occlusion (LVO) [1]. In 2015 however, when several randomized controlled trials showed safety and efficacy of endovascular treatment (EVT) for LVO stroke, the prognosis of these patients has dramatically changed. This evidence has translated into current guidelines, which recommend vascular imaging in all AIS patients upon hospital arrival. If an LVO is identified, EVT is recommended in patients who meet certain clinical inclusion criteria [2]. One of these criteria is the presence of disabling deficits, i.e., a baseline National Institutes of Health Stroke score of 6 or higher [2]. This clinical severity threshold forms the basis for clinical stroke triage tools such as the Los Angeles Motor Scale (LAMS) [3] and the Rapid Arterial Occlusion Evaluation scale (RACE) [4].

\section{Pre-hospital triage of acute ischemic stroke patients: where are we at?}

Systems of stroke care have organically grown over many decades, and as such, their set-up is unique in each country and each region. While in developing nations, healthcare systems largely lack the necessary resources and infrastructure to

Mayank Goyal

mgoyal@ucalgary.ca

1 Department of Diagnostic Imaging, University of Calgary, Calgary, Canada

2 Departments of Radiology and Clinical Neurosciences, Foothills Medical Centre, 1403 29th St. NW, Calgary, AB T2N2T9, Canada

3 Calgary, Canada

4 Division of Neuroradiology, Clinic of Radiology and Nuclear Medicine, University Hospital Basel, University of Basel, Basel, Switzerland offer EVT at all, most industrial countries have successfully established EVT networks by now. However, EVT-capable centers are mostly clustered in urban regions, while access to EVT in rural areas is either lacking or associated with long transport times. Furthermore, capacities of EVT-capable centers are limited, which often necessitates treatment of EVTineligible stroke patients to primary stroke centers (PSCs), i.e., centers that offer intravenous thrombolysis (which is also effective in recanalizing vessel occlusion albeit to a lesser degree), but not EVT. This situation has generated a transport dilemma for acute ischemic stroke patients: When is it reasonable to bypass a nearby primary stroke center, thereby potentially delaying IV thrombolysis, in favor of direct transport to an EVT-capable hospital? Conditional probability modeling suggests that within cities, direct-to-mothership paradigms are generally more time-efficient, while in rural areas with large distances to the next EVT-capable center, drip-and-ship paradigms can be beneficial [5]. Importantly, current triage paradigms will also be affected by the results of trials evaluating the role of IV thrombolysis in patients undergoing EVT: the recently published DIRECT-MT trial for instance showed non-inferior outcomes with EVT as a stand-alone treatment compared to EVT with concurrent in a direct-to-mothership scenario [6]. The results of similar trials like MR CLEAN NO IV (ISRCTN80619088) are expected soon. If EVT these trials show outcomes without concurrent IV thrombolysis to be consistently non-inferior to EVT with concurrent thrombolysis, similar trials in drip-and-ship patients might get triggered. In short, determining the optimal transport paradigm for a given patient is highly complex and depends on various factors, including transport time, workflow efficiency at the primary and comprehensive center, and accuracy of the LVO screening tool used [7]. The common goal of such clinical LVO screening tools is to aid pre-hospital patient triage by identifying AIS patients with LVO, but their accuracy is limited. Depending on the screening tool used, more than $50 \%$ of patients could still suffer from an LVO, despite a negative 
screening result [8]. Thus, oftentimes, LVO patients are not correctly recognized as such and get transported to a PSC, where vascular imaging is performed and shows the occlusion. This relatively common scenario may result in timeconsuming interhospital transfers and probably worse outcomes $[9,10]$, although more recent data from the "Direct Transfer to an Endovascular Center Compared to Transfer to the Closest Stroke Center in Acute Stroke Patients With Suspected LVO" (RACECAT) trial, which compared directto-mothership to drip-and-ship transport paradigm, suggests no difference in outcomes between the two transport paradigms [11].

\section{Emerging challenges for stroke patient triage}

With EVT indications continuously expanding, we are confronted with additional challenges in pre-hospital stroke triage. The ability of clinical pre-hospital triage tools to identify acute stroke patients who are potential EVT candidates, which was suboptimal to begin with, is likely to drop further once socalled mild or non-disabling LVO strokes, i.e., LVO patients with low baseline NIHSS, become EVT-eligible. At the time being, there is no level 1A EVT recommendation for LVO patients presenting with baseline NIHSS $<6$ yet [2]. However, LVO patients with transient deficits and/or socalled minor strokes, i.e., low NIHSS strokes, are at a high risk of early neurological decline and recurrent stroke with subsequent severe disability $[12,13]$. This might be part of the reason why the majority of physicians stated in a recent survey that they would offer EVT in low NIHSS LVO stroke [14]. Studies evaluating EVT benefit in these patients are exclusively nonrandomized and show conflicting results: While some of them suggest superior outcomes with EVT compared to medical management $[15,16]$, others found no benefit of EVT [17, 18]. The randomized IN EXTREMIS [19] and ENDO-LOW (NCT04167527) trials which investigate the safety and efficacy of EVT in minor stroke due to LVO, will hopefully provide an answer to this controversy. In light of the recent improvements in thrombectomy technology and the high rate of neurologic deterioration in LVO stroke with low baseline NIHSS (24-38\% $[20,21])$, it seems overall highly likely that these patients will be increasingly treated with EVT. Since clinical LVO screening tools are based on symptom severity, by definition, they will not be able to detect LVO patients with low NIHSS. As a result, these patients will initially be transported to a PSC, and once the LVO has been diagnosed, need to be re-routed to an EVTcapable center, which leads to substantial time delays. On the other hand, one could argue that LVO patients with low NIHSS probably have good collaterals and are so-called slow progressors, since their brain function is relatively preserved. As such, even initial admission to a PSC followed by interhospital transfer and EVT would still yield a good result. However, this line of reasoning has two major flaws. Firstly, we cannot foresee if and at which point slow progressors turn into fast progressors, which is likely determined by numerous variables such as blood pressure and sympathetic tone, some of which might be unknown in the acute setting. Secondly, outcomes will inevitably be worse with increasing time delays, and even if proportions of good outcome were to be similar, the differences could become more apparent when excellent functional status (mRS 0-1) or cognitive function measures are used as outcomes.

While high sensitivity for LVO detection is paramount, one also has to acknowledge that among all patients who are screened by emergency medical services for suspected acute stroke, the prevalence of LVO is low, at around 5\% [22]; i.e., in order not to overwhelm CSCs with non-LVO patients, a reasonably high specificity is needed.

Furthermore, EVT for medium vessel occlusions (MeVO) is moving at a rapid pace [23]. With current best medical management, MeVO stroke frequently results in severe morbidity [24], and many centers around the world therefore routinely treat MeVO strokes with EVT. At the time being, there is still lack of randomized evidence [25], but randomized trials are being planned. Detection of MeVOs, which often result in less severe clinical deficits due to their more distal occlusion location [24], will add additional challenges with regard to pre-hospital EVT triage.

In summary, it seems that with the expanding role of EVT, symptom-based pre-hospital stroke triage for endovascular treatment will soon reach a ceiling. The ability of current clinical triage tools to detect EVT candidates, which is already limited (Fig. 1a), will dramatically drop once low NIHSS LVO strokes become EVT-eligible (Fig. 1b). At the same time, omitting triage and admitting every stroke patient to an EVT-capable center is not a feasible solution either, due to various political and practical reasons, and because such an approach would by far exceed the capacities of most EVTcapable stroke centers. At first glance, simply lowering the symptom severity threshold of current clinical stroke triage tools seems like a convenient solution, since it requires no additional training or ambulance equipment and would allow us to maintain a high sensitivity for LVO strokes, but this comes at a cost of decreased specificity, i.e., a high number of EVT-ineligible patients being erroneously transported to EVT-capable centers (Fig. 1c). Clearly, more accurate solutions for pre-hospital stroke triage are needed.

\section{Beyond symptom-based stroke triage: new LVO detection technologies}

Novel pre-hospital triage technologies that are based on imaging findings or analysis of parenchymal activity, are able to overcome the inherent limitations of symptom-based 

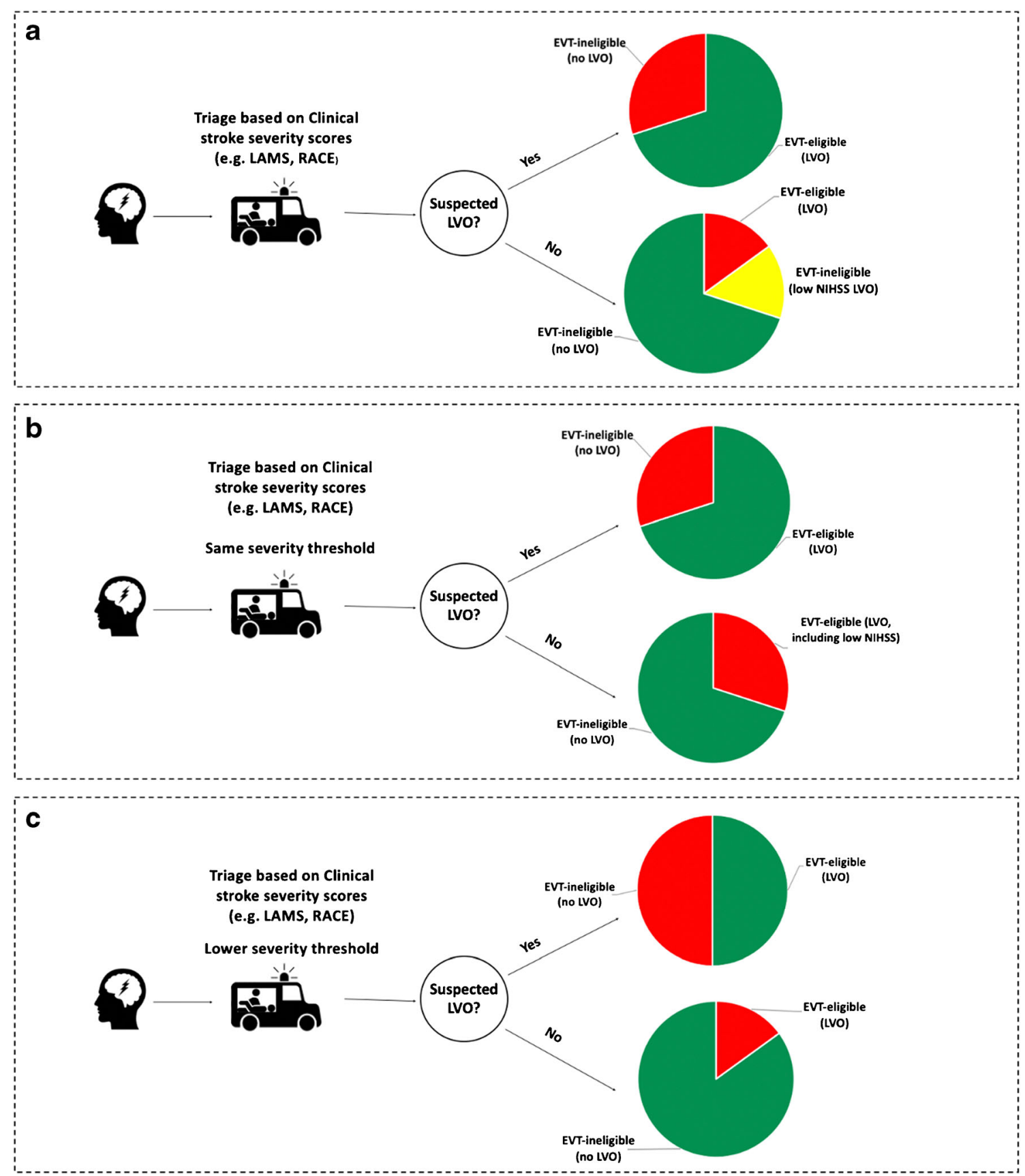

Fig. 1 Pre-hospital EVT triage based on clinical symptom severity scores. a Current pre-hospital EVT triage situation. b Expected challenges with currently established pre-hospital LVO triage algorithms once EVT for low NIHSS LVO stroke has been established. Many LVO patients with low NIHSS will be erroneously identified as EVT-ineligible and transported to a PSC, which means they will have to undergo interhospital transfer in order to receive EVT. c Expected challenges when

stroke triage, since they do not rely on clinical deficits (suppl. table 1).

Mobile stroke units (MSU), i.e., ambulances that are equipped with a CT scanner, allow for direct visualization of the occluded blood vessel in the field [26]. At the time being, only few MSUs are equipped with CT angiography capacities, maintaining currently established clinical pre-hospital LVO triage tools with lower symptom thresholds once EVT for low NIHSS LVO stroke has been established. Lowering symptom severity thresholds of clinical LVO screening tools will maintain sensitivity for detection of EVT candidates, but this comes at a cost of decreased specificity; i.e., many nonLVO patients will get erroneously admitted to a CSC, which might overwhelm CSC capacities

but depending on the demand, this might change soon [27]. LVOs can sometimes be seen even on non-contrast CT when using the right slice thickness and reconstruction kernel, and with newer technologies, better imaging quality, and machine learning-based algorithms, it might also become possible to reliably and consistently detect intracranial occlusions on non- 
contrast CT [28]. This would obviate the need for CTA capacities and facilitate imaging in the MSU, as non-contrast CT imaging can be performed by trained technicians in many jurisdictions, whereas for contrast-enhanced studies, a physician usually has to be present [29]. That being said, MSU staff requirements, acquisition, and maintenance costs are substantial, and depending on the distance of the MSU home base to the patient's location, use of an MSU might result in substantially longer travel times compared to a "conventional" ambulance [30].

Smaller, portable devices would constitute a more practical solution, as they could be installed in regular ambulances. First studies on transcranial Doppler ultrasound for LVO detection have shown encouraging results $[31,32]$, but in practice, performing the exam is often difficult due to an insufficient acoustic window [33]. MeVO detection using ultrasound-based technologies will be even more challenging. Electroencephalography (EEG)-based techniques [34] have also shown promise. As opposed to ultrasound, they rely on parenchymal signal alterations rather than detection of the occlusion site itself. One potential problem of this approach is that relative preservation of brain function, as it is the case in patients with mild clinical deficits, might not result in signal abnormalities that are conspicuous enough to be detected. However, once refined and appropriately validated, one or more of these technologies will hopefully allow for efficient detection of EVT candidates independent of clinical deficits. Cost-effectiveness is another important point to consider when deciding about the optimal triage technology. One advantage of the currently used tools is that they entail no costs for additional equipment. Modeling of pre-hospital stroke triage and transport routes is now possible and could help local hospitals and policymakers to decide about the optimal prehospital triage strategy for their local environment given their available resources and keeping all factors, including cost-effectiveness, in mind $[35,36]$.

\section{Time to think ahead}

It is important to note that all of the above-mentioned technologies are still in their infancy and far from being used in clinical routine. However, with constant improvements in EVT technology and expanding treatment indications, it becomes obvious that EVT candidates cannot be reliably distinguished from EVT-ineligible patients solely based on clinical deficits. Pre-hospital stroke triage will need to accommodate to this new reality. Should we wait for definitive evidence of EVT benefit for minor strokes, or should we prepare ahead of time? We personally believe that we should start right now, by developing and testing alternative pre-hospital triage tools, understanding ambulance design, interacting with emergency medical services providers, and augmenting the capacities of
EVT-capable stroke centers, since it is likely that more and more acute ischemic stroke patients will become potential EVT candidates.

Supplementary Information The online version contains supplementary material available at https://doi.org/10.1007/s00234-021-02638-6.

\section{Compliance with ethical standards}

Conflict of interest Mayank Goyal is a consultant for Medtronic, Stryker, Microvention, Mentice, and GE Healthcare and holds a licensing agreement with GE Healthcare regarding systems of acute stroke diagnosis. The remaining author has nothing to disclose.

Ethical approval Ethics approval was not necessary since this manuscript does not involve any patient or animal data.

Informed consent Informed consent was not obtained since this manuscript does not involve any patient data.

\section{References}

1. Goyal M, Menon BK, van Zwam WH, Dippel DW, Mitchell PJ, Demchuk AM, Davalos A, Majoie CB, van der Lugt A, de Miquel MA, Donnan GA, Roos YB, Bonafe A, Jahan R, Diener HC, van den Berg LA, Levy EI, Berkhemer OA, Pereira VM, Rempel J, Millan M, Davis SM, Roy D, Thornton J, Roman LS, Ribo M, Beumer D, Stouch B, Brown S, Campbell BC, van Oostenbrugge RJ, Saver JL, Hill MD, Jovin TG, collaborators H (2016) Endovascular thrombectomy after large-vessel ischaemic stroke: a meta-analysis of individual patient data from five randomised trials. Lancet 387 (10029):1723-1731. doi:https://doi.org/10.1016/ S0140-6736(16)00163-X

2. Powers WJ, Rabinstein AA, Ackerson T, Adeoye OM, Bambakidis NC, Becker K, Biller J, Brown M, Demaerschalk BM, Hoh B, Jauch EC, Kidwell CS, Leslie-Mazwi TM, Ovbiagele B, Scott PA, Sheth KN, Southerland AM, Summers DV, Tirschwell DL (2019) Guidelines for the early management of patients with acute ischemic stroke: 2019 update to the 2018 guidelines for the early management of acute ischemic stroke: a guideline for healthcare professionals from the American Heart Association/American Stroke Association. Stroke 50(12):e344-e418. https://doi.org/10. 1161/STR.0000000000000211

3. Nazliel B, Starkman S, Liebeskind DS, Ovbiagele B, Kim D, Sanossian N, Ali L, Buck B, Villablanca P, Vinuela F, Duckwiler G, Jahan R, Saver JL (2008) A brief prehospital stroke severity scale identifies ischemic stroke patients harboring persisting large arterial occlusions. Stroke 39(8):2264-2267. https://doi.org/10. 1161/STROKEAHA.107.508127

4. Perez de la Ossa N, Carrera D, Gorchs M, Querol M, Millan M, Gomis M, Dorado L, Lopez-Cancio E, Hernandez-Perez M, Chicharro V, Escalada X, Jimenez X, Davalos A (2014) Design and validation of a prehospital stroke scale to predict large arterial occlusion: the rapid arterial occlusion evaluation scale. Stroke 45(1):87-91. https://doi.org/10.1161/STROKEAHA.113.003071

5. Holodinsky JK, Almekhlafi MA, Goyal M, Kamal N (2018) Mathematical modeling for decision-making in the field for acute stroke patients with suspected large vessel occlusion. Stroke: STROKEAHA118021381. doi:https://doi.org/10.1161/ STROKEAHA.118.021381 
6. Yang P, Zhang Y, Zhang L, Zhang Y, Treurniet KM, Chen W, Peng Y, Han H, Wang J, Wang S, Yin C, Liu S, Wang P, Fang Q, Shi H, Yang J, Wen C, Li C, Jiang C, Sun J, Yue X, Lou M, Zhang M, Shu H, Sun D, Liang H, Li T, Guo F, Ke K, Yuan H, Wang G, Yang W, Shi H, Li T, Li Z, Xing P, Zhang P, Zhou Y, Wang H, Xu Y, Huang Q, Wu T, Zhao R, Li Q, Fang Y, Wang L, Lu J, Li Y, Fu J, Zhong X, Wang Y, Wang L, Goyal M, Dippel DWJ, Hong B, Deng B, Roos Y, Majoie C, Liu J, Investigators DM (2020) Endovascular thrombectomy with or without intravenous alteplase in acute stroke. N Engl J Med 382(21):1981-1993. https:// doi.org/10.1056/NEJMoa2001123

7. Holodinsky JK, Williamson TS, Demchuk AM, Zhao H, Zhu L, Francis MJ, Goyal M, Hill MD, Kamal N (2018) Modeling stroke patient transport for all patients with suspected large-vessel occlusion. JAMA Neurol 75(12):1477-1486. https://doi.org/10.1001/ jamaneurol.2018.2424

8. Smith EE, Kent DM, Bulsara KR, Leung LY, Lichtman JH, Reeves MJ, Towfighi A, Whiteley WN, Zahuranec DB, American Heart Association Stroke C (2018) Accuracy of prediction instruments for diagnosing large vessel occlusion in individuals with suspected stroke: a systematic review for the 2018 guidelines for the early management of patients with acute ischemic stroke. Stroke 49(3): e111-e122. https://doi.org/10.1161/STR.0000000000000160

9. Froehler Michael T, Saver Jeffrey L, Zaidat Osama O, Jahan R, Aziz-Sultan Mohammad A, Klucznik Richard P, Haussen Diogo C, Hellinger Frank R, Yavagal Dileep R, Yao Tom L, Liebeskind David S, Jadhav Ashutosh P, Gupta R, Hassan Ameer E, Martin Coleman O, Bozorgchami H, Kaushal R, Nogueira Raul G, Gandhi Ravi H, Peterson Eric C, Dashti Shervin R, Given Curtis A, Mehta Brijesh P, Deshmukh V, Starkman S, Linfante I, McPherson Scott H, Kvamme P, Grobelny Thomas J, Hussain Muhammad S, Thacker I, Vora N, Chen Peng R, Monteith Stephen J, Ecker Robert D, Schirmer Clemens M, Sauvageau E, Abou-Chebl A, Derdeyn Colin P, Maidan L, Badruddin A, Siddiqui Adnan H, Dumont Travis M, Alhajeri A, Taqi MA, Asi K, Carpenter J, Boulos A, Jindal G, Puri Ajit S, Chitale R, Deshaies Eric M, Robinson David H, Kallmes David F, Baxter Blaise W, Jumaa Mouhammad A, Sunenshine P, Majjhoo A, English Joey D, Suzuki S, Fessler Richard D, Delgado Almandoz Josser E, Martin Jerry C, Mueller-Kronast Nils H (2017) Interhospital Transfer Before Thrombectomy Is Associated With Delayed Treatment and Worse Outcome in the STRATIS Registry (Systematic Evaluation of Patients Treated With Neurothrombectomy Devices for Acute Ischemic Stroke). Circulation 136(24):2311-2321. https://doi.org/10.1161/CIRCULATIONAHA.117.028920

10. Venema E, Groot AE, Lingsma HF, Hinsenveld W, Treurniet KM, Chalos V, Zinkstok SM, Mulder M, de Ridder IR, Marquering HA, Schonewille WJ, Wermer MJH, Majoie C, Roos Y, Dippel DWJ, Coutinho JM, Roozenbeek B (2019) Effect of interhospital transfer on endovascular treatment for acute ischemic stroke. Stroke 50(4): 923-930. https://doi.org/10.1161/STROKEAHA.118.024091

11. Ribo M (2020) RACECAT results presented at ESO-WSO 2020. Accessed December 62020

12. Coutts SB, Moreau F, Asdaghi N, Boulanger JM, Camden MC, BCV C, Demchuk AM, Field TS, Goyal M, Krause M, Mandzia J, Menon BK, Mikulik R, Penn AM, Swartz RH, Hill MD, Diagnosis of Uncertain-Origin Benign Transient Neurological Symptoms Study G (2019) Rate and prognosis of brain ischemia in patients with lower-risk transient or persistent minor neurologic events. JAMA Neurol 76(12):1439-1445. https://doi.org/10.1001/ jamaneurol.2019.3063

13. Lee VH, Thakur G, Nimjee SM, Youssef PP, Lakhani S, Heaton S, Powers CJ (2020) Early neurologic decline in acute ischemic stroke patients receiving thrombolysis with large vessel occlusion and mild deficits. J Neurointerv Surg 12(11):1085-1087. https://doi. org/10.1136/neurintsurg-2020-015871
14. Ospel JM, Kim B, Heo JH, Yoshimura S, Kashani N, Menon B, Almekhlafi M, Demchuk A, Hill M, Saposnik G, Goyal M (2020) Endovascular treatment decision-making in acute ischemic stroke patients with large vessel occlusion and low National Institutes of Health Stroke Scale: insights from UNMASK EVT, an international multidisciplinary survey. Neuroradiology 62(6):715-721. https:// doi.org/10.1007/s00234-020-02371-6

15. Bhogal P, Bucke P, Ganslandt O, Bazner H, Henkes H, Perez MA (2016) Mechanical thrombectomy in patients with M1 occlusion and NIHSS score $</=5$ : a single-centre experience. Stroke Vasc Neurol 1(4):165-171. https://doi.org/10.1136/svn-2016-000052

16. Nagel S, Bouslama M, Krause LU, Kupper C, Messer M, Petersen M, Lowens S, Herzberg M, Ringleb PA, Mohlenbruch MA, Tiedt S, Lima FO, Haussen DC, Smith WS, Lev MH, Nogueira RG (2018) Mechanical thrombectomy in patients with milder strokes and large vessel occlusions. Stroke 49(10):2391-2397. https://doi. org/10.1161/STROKEAHA.118.021106

17. Sarraj A, Hassan A, Savitz SI, Grotta JC, Cai C, Parsha KN, Farrell CM, Imam B, Sitton CW, Reddy ST, Kamal H, Goyal N, Elijovich L, Reishus K, Krishnan R, Sangha N, Wu A, Costa R, Malik R, Mir O, Hasan R, Snodgrass LM, Requena M, Graybeal D, Abraham M, Chen M, McCullough LD, Ribo M (2018) Endovascular thrombectomy for mild strokes: how low should we go? Stroke 49(10):2398-2405. https://doi.org/10.1161/STROKEAHA.118. 022114

18. Volny O, Zerna C, Tomek A, Bar M, Rocek M, Padr R, Cihlar F, Nevsimalova M, Jurak L, Havlicek R, Kovar M, Sevcik P, Rohan V, Fiksa J, Cernik D, Jura R, Vaclavik D, Cimflova P, Puig J, Dowlatshahi D, Khaw AV, Fainardi E, Najm M, Demchuk AM, Menon BK, Mikulik R, Hill MD (2020) Thrombectomy vs medical management in low NIHSS acute anterior circulation stroke. Neurology. 95:e3364-e3372. https://doi.org/10.1212/WNL. 0000000000010955

19. EXTREMIS I. https://www.inextremis-study.com. Accessed October 132020

20. Kim JT, Park MS, Chang J, Lee JS, Choi KH, Cho KH (2013) Proximal arterial occlusion in acute ischemic stroke with low NIHSS scores should not be considered as mild stroke. PLoS One 8(8):e70996. https://doi.org/10.1371/journal.pone.0070996

21. Rajajee V, Kidwell C, Starkman S, Ovbiagele B, Alger JR, Villablanca P, Vinuela F, Duckwiler G, Jahan R, Fredieu A, Suzuki S, Saver JL (2006) Early MRI and outcomes of untreated patients with mild or improving ischemic stroke. Neurology 67(6): 980-984. https://doi.org/10.1212/01.wnl.0000237520.88777.71

22. Dozois A, Hampton L, Kingston CW, Lambert G, Porcelli TJ, Sorenson D, Templin M, VonCannon S, Asimos AW (2017) PLUMBER Study (Prevalence of Large Vessel Occlusion Strokes in Mecklenburg County Emergency Response). Stroke 48(12): 3397-3399. https://doi.org/10.1161/STROKEAHA.117.018925

23. Goyal M, Ospel JM, Menon BK, Hill MD (2020) MeVO: the next frontier? J Neurointerv Surg. 12:545-547. https://doi.org/10.1136/ neurintsurg-2020-015807

24. Ospel JM, Menon BK, Demchuk AM, Almekhlafi MA, Kashani N, Mayank A, Fainardi E, Rubiera M, Khaw A, Shankar JJ, Dowlatshahi D, Puig J, Sohn SI, Ahn SH, Poppe A, Calleja A, Hill MD, Goyal M (2020) Clinical course of acute ischemic stroke due to medium vessel occlusion with and without intravenous alteplase treatment. Stroke:STROKEAHA120030227. doi:https:// doi.org/10.1161/STROKEAHA.120.030227

25. Almekhlafi M, Ospel JM, Saposnik GN, Kashani N, Demchuk AM, Hill MD, Goyal M, Menon BK (2019) Endovascular treatment decisions in patients with M2 segment MCA occlusions. AJNR

26. Fassbender K, Grotta JC, Walter S, Grunwald IQ, RagoschkeSchumm A, Saver JL (2017) Mobile stroke units for prehospital thrombolysis, triage, and beyond: benefits and challenges. Lancet 
Neurol 16(3):227-237. https://doi.org/10.1016/S1474-4422(17) 30008-X

27. Kettner M, Helwig SA, Ragoschke-Schumm A, Schwindling L, Roumia S, Keller I, Martens D, Kulikovski J, Manitz M, Lesmeister M, Walter S, Grunwald IQ, Schlechtriemen T, Reith W, Fassbender K (2017) Prehospital computed tomography angiography in acute stroke management. Cerebrovasc Dis 44(5-6): 338-343. https://doi.org/10.1159/000484097

28. Riedel CH, Zoubie J, Ulmer S, Gierthmuehlen J, Jansen O (2012) Thin-slice reconstructions of nonenhanced CT images allow for detection of thrombus in acute stroke. Stroke 43(9):2319-2323. https://doi.org/10.1161/STROKEAHA.112.649921

29. Ernst M, Romero JM, Buhk JH, Kemmling A, Fiehler J, Groth M (2014) Sensitivity of visual and quantitative detection of middle cerebral artery occlusion on non-contrast-enhanced computed tomography. Neuroradiology 56(12):1063-1068. https://doi.org/10. 1007/s00234-014-1443-y

30. Holodinsky JK, Kamal N, Zerna C, Ospel JM, Zhu L, Wilson AT, Hill MD, Goyal M (2020) In what scenarios does a mobile stroke unit predict better patient outcomes?: a modeling study. Stroke 51(6):1805-1812. https://doi.org/10.1161/STROKEAHA.119. 028474

31. Antipova D, Eadie L, Macaden AS, Wilson P (2019) Diagnostic value of transcranial ultrasonography for selecting subjects with large vessel occlusion: a systematic review. Ultrasound J 11(1): 29. https://doi.org/10.1186/s13089-019-0143-6

32. Lima FO, Mont'Alverne FJA, Bandeira D, Nogueira RG (2019) Pre-hospital assessment of large vessel occlusion strokes: implications for modeling and planning stroke systems of care. Front Neurol 10:955. https://doi.org/10.3389/fneur.2019.00955

33. Antipova D, Eadie L, Makin S, Shannon H, Wilson P, Macaden A (2020) The use of transcranial ultrasound and clinical assessment to diagnose ischaemic stroke due to large vessel occlusion in remote and rural areas. PLoS One 15(10):e0239653. https://doi.org/10. 1371/journal.pone. 0239653

34. Shreve L, Kaur A, Vo C, Wu J, Cassidy JM, Nguyen A, Zhou RJ, Tran TB, Yang DZ, Medizade AI, Chakravarthy B, Hoonpongsimanont W, Barton E, Yu W, Srinivasan R, Cramer SC (2019) Electroencephalography measures are useful for identifying large acute ischemic stroke in the emergency department. J Stroke Cerebrovasc Dis 28(8):2280-2286. https://doi.org/10.1016/ j.jstrokecerebrovasdis.2019.05.019

35. Venema E, Lingsma HF, Chalos V, Mulder M, Lahr MMH, van der Lugt A, van Es A, Steyerberg EW, Hunink MGM, Dippel DWJ, Roozenbeek B (2019) Personalized prehospital triage in acute ischemic stroke. Stroke 50(2):313-320. https://doi.org/10.1161/ STROKEAHA.118.022562

36. Xu Y, Parikh NS, Jiao B, Willey JZ, Boehme AK, Elkind MSV (2019) Decision analysis model for prehospital triage of patients with acute stroke. Stroke 50(4):970-977. https://doi.org/10.1161/ STROKEAHA.118.023272

Publisher's note Springer Nature remains neutral with regard to jurisdictional claims in published maps and institutional affiliations. 